\title{
Don't miss the plenary sessions
}

\author{
Fred A. Crawford, Jr, MD
}

\author{
From the Division of Cardiothoracic Surgery, Medical University of South Carolina, Charleston, SC. \\ Disclosures: Author has nothing to disclose with regard to commercial support. \\ Received for publication Sept 9, 2015; accepted for publication Sept 9, 2015; available ahead of print Oct 15 , \\ 2015 . \\ Address for reprints: Fred A. Crawford, Jr, MD, Division of Cardiothoracic Surgery, Medical University of South \\ Carolina, 171 Ashley Ave, Charleston, SC 29425 (E-mail: crawfrdf@musc.edu). \\ J Thorac Cardiovasc Surg 2016;151:35-6 \\ 0022-5223/\$36.00 \\ Copyright (C) 2016 by The American Association for Thoracic Surgery \\ http://dx.doi.org/10.1016/j.jtcvs.2015.09.039
}

Terasaki and colleagues ${ }^{1}$ reviewed American Association for Thoracic Surgery (AATS) Annual Meeting programs from 1994 through 2014 and compared presentations made at the plenary sessions to contemporary articles published in the Journal. Using the Web of Science citation index to rank these articles, they conclude that articles presented in plenary sessions are more highly cited than other contemporary work. This is very interesting and confirms the wisdom of the Annual Meeting Program Committee. Currently the Program Committee is composed of 25 well-known and recognized experts in the various areas of cardiothoracic surgery. They volunteer many hours of time reviewing (blinded to both the authors and the institutions) abstracts submitted for presentation at the AATS Annual Meeting, and then they meet for hours in December to decide which abstracts should be selected for presentation. The very best abstracts - those involving cuttingedge studies and representing the various domains of the specialty-are selected to be presented at the plenary sessions. Plenary sessions are held on Monday and Tuesday mornings of the AATS Annual Meeting. There are no competing breakout sessions and exhibits are not open during these sessions. Accordingly, they are very well attended by meeting attendees. Given the rigorous selection process and the Committee's desire to have the very best science presented at the plenary sessions, it is not surprising that when published this work is more-often cited than other articles published in the Journal and in fact turn out to be what Terasaki and colleagues call "some of the seminal studies in our field in the last 20 years."

The authors correctly point out some of the potential problems with their study, particularly the bias for older articles. Simply stated, articles published in 1994 have had 20 years to be cited, whereas articles published in 2014 have had only 1 year. O'Sullivan and colleagues ${ }^{2}$ point out other factors that influence the citation index, including "impact disparity," "obliteration by incorporation," and discrepancies involving citation practice among disciplines and authors. Nevertheless, citation reviews are currently the best and most frequently used technique to judge the

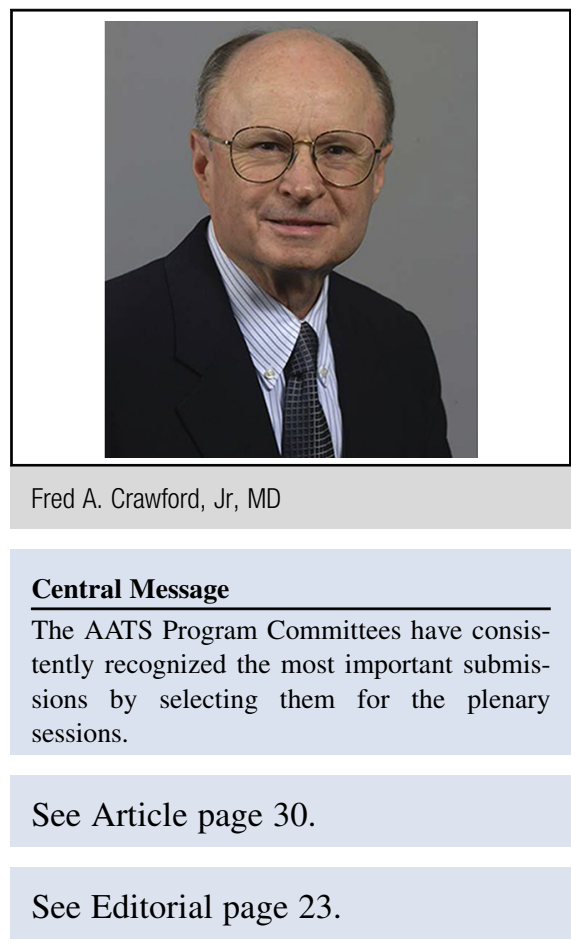

importance of a publication (and a journal). Terasaki and colleagues compared plenary session submissions to articles published in the same issue of the Journal. Perhaps a better comparison might have been to "nonplenary" reports presented at the same meeting in breakout sessions and subsequently published.

The first AATS Annual Meeting took place in 1917 and the Journal of Thoracic and Cardiovascular Surgery (established in 1931) were the first meeting and publication, respectively, in the world dedicated solely to cardiothoracic surgery. Now there are numerous other organizations and journals dedicated to the specialty. There were 5 papers presented at the first meeting (all related to empyema) compared with 112 major papers presented in 2014, not including forum papers, poster presentations, latebreaking clinical trials, and videos, among others.

My first experience with the AATS Annual Meeting was its 50th anniversary meeting in 1967. I was a senior medical student and I presented a paper. At that meeting, 50 papers were presented. All sessions were plenary-there were no breakout sessions for subspecialties. Simultaneous sessions first occurred in 1991 and were limited to adult cardiac, congenital, and general thoracic sessions. As the specialty has grown, the number of breakout sessions has dramatically increased, reflecting not only the core subspecialties of adult cardiac, congenital cardiac, 
and general thoracic, but also newer subspecialties such as education, endovascular techniques, critical care, and transplantation.

Despite these changes, plenary sessions and the papers presented there remain a critically important part of the Annual Meeting as demonstrated by Terasaki and colleagues. Other cardiothoracic surgery organizations emphasize the importance of plenary session papers by recognizing them with named awards (eg, J. Maxwell Chamberlin and Richard Clark papers). Given the importance of the work presented at these plenary sessions as documented in this article, perhaps it is time for the
AATS to also recognize the importance of these presentations and papers with named awards. Whether or not this occurs, the AATS Annual Meeting will continue to evolve with the specialty, but hopefully these plenary sessions will never be abandoned.

\section{References}

1. Kamel M, Terasaki Y, Adusumilli PS, Stiles BM. Plenary presentations and public citations from The American Association for Thoracic Surgery. J Thorac Cardiovasc Surg. 2016;151:30-4.

2. O'Sullivan KE, Kelly JC, Hurley JP. The 100 most cited publications in cardiac surgery: a bibliometric analysis. Ir J Med Sci. 2015;184:91-9. 